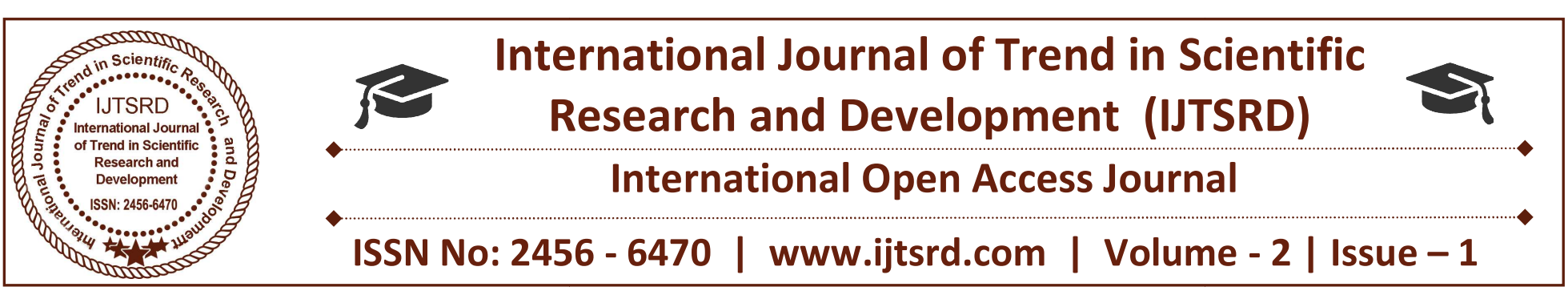

\title{
Human Resource Information System: A Theoretical Perspective
}

\author{
Mr. Harish Tigari, M.Com., PGDMM., D.Ed
}

Faculty Member, Department of Commerce, Davangere University, Shivagangotri, Davangere

\begin{abstract}
The individual or group of individuals who are involved in production function with continuous achievement with the attributes of a productive person in terms of skill, knowledge, talent, caliber, capacity to do a task, and other competencies etc, are the collective features of employees; it can also be called as a human resource. The treatment of workforce in ancient periods was like a commodity but now in strategic human resource management era, the workforce is treated as an asset to the organization. The move from commodity concept to the human asset or human capital management creates wide scope for management of people in the organization in an efficient and effective manner, in this context the present study attempts to analyze the application of management information system in managing human resource i.e. the human resource information system. The present study addresses the conceptual framework of the human resource information system which includes nature, benefits, and HRIS data, Strategic Human Resource Planning and HRIS, Productive HRIS. The study is based on both primary data and secondary data.
\end{abstract}

Keywords: Information system, HRIS, Benefits of HRIS, Productive HRIS, SHRP

\section{INTRODUCTION}

One of the significant functional areas of the management is managing the people in an organization. It refers to the process of acquiring the required human resource after that providing extensive training and development thereby improve their skills and efficiency, maintaining the compensatory issues and finally separate the human resource based on the functional specification. Now a day in the modern era the management of human resource takes different deviations relating to its functional areas and also tremendous changes take place in managing the people in the organization. Such changes like the convergence of human resource planning as talent management, wage administration as total reward management, move from commodity concept to human asset or human capital management, human resource accounting, human resource research, human resource audit, and human resource information system. One of the emerging paradigms in modern human resource management is the human resource information system; it can also be called an electronic human resource management, human resource information management system, and human resource management system. It is a database which consists different type's data about the organization workforce like employee wage, salary, incentives, performance, awards, and rewards etc. The human resource information system is the process of collecting, recording, retrieving, accessing, integrating, and maintaining the data about a human resource in an organization, in other words, it is the system which provides the information about the human resource to the management to take a rational decision about functional activities of the HRM. It is a system which consists of interrelated components in the form of a database which helps to manage the workforce in an efficient manner.

\section{OBJECTIVES OF THE STUDY}

$>$ To analyze the employee satisfaction about human resource information system.

$>$ To understand the relationship between the SHRP and HRIS. 


\section{METHODOLOGY OF THE STUDY}

The present study is based on both primary and secondary data. The structured questionnaire was prepared based on Likert scale technique with five points and ten questions on employee opinion and perception towards the HRIS. The questionnaires were distributed to seventy employees in different private organizations. The secondary data collected from different books, journals, articles, research papers and internet source also.

\section{NEED FOR THE STUDY}

The traditional era of human resource management with the manual maintenance of documentation creates difficulty in analyzing, inaccuracy in data, inconsistency, data insecurity, disintegration and costly exercise. This hurdle creates a wide scope for the emergence of the human resources information system. The tremendous change takes place in information and communication technology with advancement, creates a digital platform to collect, store, retrieve, maintain and communicate the data to users. So in this context, the present study intends to analyze human resources information system

\section{REVIEW OF LITERATURE}

1. (Geraldine DeSanctis 1986) HRIS have become a major MIS subfunction within the personnel area so f many large corporations. The HRIS is designed to support the planning, administration, decisionmaking, and control activities of human resources management.

2. (John W. Boudreau 1996)To encourage moving beyond the traditional administrative model of
HRIS, consider three ways that the HRIS makes a difference in organizations, such as Calculation, Communication, and Change.

3. (Nicholas Aston Beadles 2005)The use of HRIS has been advocated as an opportunity for human resource (HR) professionals to become strategic partners with top management.

4. (Ebenezer Ankrah, Evans Sokro 2012)HRIS use contributes a great deal to enhance variables such as cost and time savings (CTS), decision-making contributions (DMC), quality information effects (QIE) employee development commitment (EDC).

5. (Patricia L Riley \& et al 2012) HRIS are critical for evidence-based human resource policy and practice; there is a dearth of information about these systems, including their current capabilities.

6. (J. Anitha and M. Aruna 2013) Human Resource Information Systems (HRIS) is of profound significance in managing Human Resources in the contemporary globalized knowledge economy. It integrates with the other functions of HR striving for business excellence.

7. (Sabrina Jahan 2014)The HRIS merges HRM as a discipline and in particular, it's basic HR activities and processes in the information technology field. It can be used to maintain details such as employee profiles, absence reports, salary administration and various kinds of reports.

8. (Halil Buzkan 2016)The strategic implementation of HRIS would improve the perceived standing of HR professionals and executives within their organizations as HRIS provides added value and increases the status of the HR profession as a whole.

\section{ANALYSIS \& INTERPRETATION}

Table - 1 Employees response on HRIS in selected Private organizations

\begin{tabular}{|l|l|l|l|l|l|l|l|}
\hline S.No & Hypothesis & SD \% & D \% & N \% & A \% & SA \% & Total \\
\hline $\mathbf{1}$ & Requires long hour of training & 9 & 51 & 29 & 11 & 0 & $100 \%$ \\
\hline $\mathbf{2}$ & Easy to understand & 0 & 0 & 6 & 43 & 51 & $100 \%$ \\
\hline $\mathbf{3}$ & Requires high technical knowledge & 9 & 37 & 20 & 31 & 3 & $100 \%$ \\
\hline $\mathbf{4}$ & Employee friendly & 0 & 5 & 15 & 54 & 26 & $100 \%$ \\
\hline $\mathbf{5}$ & Increase transparency & 0 & 3 & 14 & 49 & 34 & $100 \%$ \\
\hline $\mathbf{6}$ & Easy Performance Evaluation & 0 & 0 & 6 & 23 & 71 & $100 \%$ \\
\hline $\mathbf{7}$ & Formulating payroll & 0 & 0 & 14 & 52 & 34 & $100 \%$ \\
\hline $\mathbf{8}$ & Decrease absenteeism turnover & 6 & 5 & 32 & 37 & 20 & $100 \%$ \\
\hline $\mathbf{9}$ & Creates Satisfaction & 0 & 0 & 0 & 40 & 60 & $100 \%$ \\
\hline
\end{tabular}

Source: Field survey

SD- Strongly Disagree, D- disagree, SA- Strongly agree, A- Agree, N-Neutral 
International Journal of Trend in Scientific Research and Development (IJTSRD) ISSN: 2456-6470

HRIS and training period: The nine percent employees strongly disagree, fifty-one percent they disagree, and twenty-nine percent they are neutral and eleven percent they agree about hypothesis i.e. it requires a long hour of training. So it is clear that the HRIS not required a long hour of training.

HRIS and adaptability: The second aspect in the table reveals that fifty-one percent of the respondents are strongly agreed, forty-three percent they agree, and only six percent they don't say anything about adaptability and understanding of HRIS. Thus HRIS is easy to understand and adapt.

HRIS and technical knowledge: Only thirty-four percent they agree about the aspect i.e. it requires high technical knowledge, but forty-six percent they disagree about the aspect. Thus it indicates that there is no requirement of high technical knowledge to operate HRIS.

HRIS is Employee friendly: Twenty-six percent of the respondents are strongly agreed and fifty-four percent are agreed about the hypothesis i.e. the HRIS is employee friendly means user-friendly.

HRIS helps increase transparency: Thirty-four percent of the respondents they strongly agree about the hypothesis and forty-nine percent they agree. Thus it's clear that Human Resource Information Systems helps to increase transparency.

HRIS and Performance evaluation: Seventy-one percent of the respondents they strongly agree and twenty-three they agree and states that the Human Resource Information Systems helps to evaluate the performance of the employees.

HRIS and payroll: The Human Resource Information Systems helps to formulate payroll for the employee thirty-four percent they strongly agree and fifty-two percent they agree about this aspect.

HRIS and absenteeism turnover: The Human Resource Information Systems helps to decrease the absenteeism turnover. Twenty percent they strongly agree and thirty-seven percent they agree about this hypothesis.

HRIS and Employees satisfaction: The above table reveals the employee's response to HRIS in selected private organizations. The sixty percent of employees they strongly agree and forty percent they agree about satisfaction by using HRIS.

\section{CONCEPTUAL FRAMEWORK}

\section{Human Resource Information System (HRIS)}

The system refers to the systematic arrangement of interrelated components or elements. The HRIS provides the plethora of information about the human resource in the organization to the users to take rational decisions relating to human resource. It can also be called as a human resource information management system. It helps to conduct all the functional areas of human resource management in a cost-effective manner. The following are the alternative names for Human Resource Information System (HRIS).

$>$ Human Resource Management Systems (HRMS).

$>$ E-Human Resource Information Systems (EHRIS).

$>$ Human Resource Information Systems (HRIS).

$>$ Human Resource Management Information Systems (HRMIS).

$>$ Employee Information System(EIS)

$>$ Personnel Management Information Systems (PMIS).

\section{Few Examples of Human Resource Information System in Indian Scenario}

Coal India Ltd: The Online HRIS has been introduced wherein all the Executives of CIL \& its subsidiaries can access various modules of HRIS like Performance Management System, Learning \& Development, Family Details, Experience/ Skill.

$>$ Prasar Bharti: The objective HRIS is to have an accurate, comprehensive, up-to-date online record of all employees of Prasar Bharati. This can be used for improving the management of personnel at different levels and locations.

> State Bank of India: SBI HRMS Portal Login specially developed for their Employees to check Salary and Pension slip statement PF, gratuity at the website. SBI also launched MYHRMS mobile app for their employees to access HRMS sbi portal anywhere.

> Panjab National Bank: HRMS provides a plethora of functions like Performance Appraisal, Attendance, HR Management Information System, Training Management, Employee Selection and Promotion Process, Employee Self Service and Absence Management. 


\section{Benefits of Human Resource Information System (HRIS)}

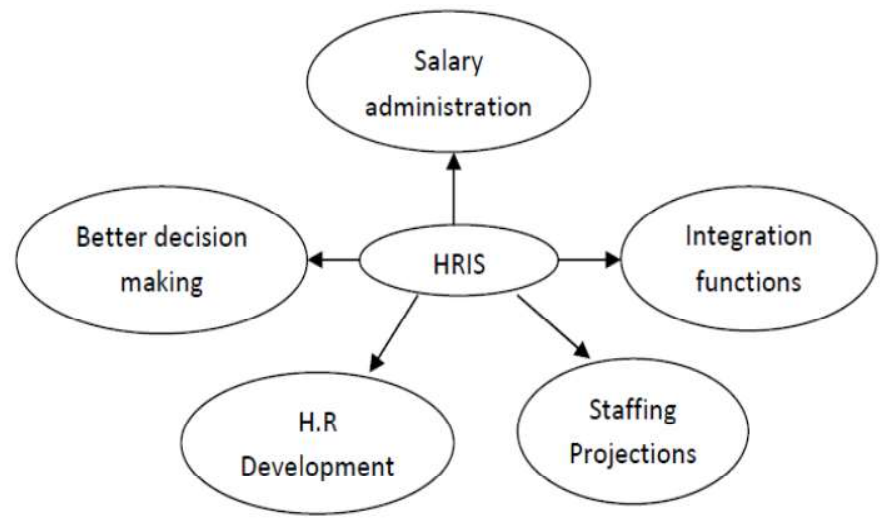

Better decision making: The human resource information system helps to take a better decision about all managerial and operative functions of human resource management. The better decision is based on cost and benefit analysis means time and cost associated with electronic management of human resource.

Salary administration: The effective and efficient wage or salary administration is possible only when the organizations adopt the information system in their functional areas. The human resource information system consists the data about individual employees' salary, wage, and other compensatory aspects.

Integration function: The important function of the human resource information system is it helps to integrate the information technology with Human resource functions in order to make a rational decision about human capital in the organization. The information system helps to coordinate all HR activities with technology in a single platform.

Human Resource Development: The HRIS helps to develop human resource in an organization by considering a data-driven approach which enables the statistics about performance, past achievements, awards, and rewards. The HRIS helps to provide extensive training and development thereby enhancing the skills and other specifications.

Staffing projections: The primal operative function of the human resource management is manpower planning which helps estimate the future requirements of human resource in an organization. The HRIS provides the data about the requirement of human resource in an organization by analyzing the absenteeism, turnover, retirement etc.
HRIS and Strategic human resource planning: Strategy refers to the long-term plan designed to achieve desired objectives. We can classify the strategies like businesses strategies, functional strategies, corporate strategies etc. The Strategic Human Resource Management refers to the process of aligning the business strategy with HR strategy. The Strategic Human Resource Management consists of different elements like strategic human resource planning (SHRP), Strategic performance management (SPM), Strategic training and development (S\&TD), Strategic compensation and reward management(SCRM), among these the strategic human resource planning(SHRP), is a primal function which helps to identify the key positions in the organization which very essential to achieve organizational objectives. The integration of information system with human resource planning creates an opportunity to make rational decisions on HR issues. Hanadi AlZeiger in his study investigates the link between human resource information system and strategic human resource planning by suggesting the model with independent variables in HRIS like human resource development, staffing, compensation and benefits, Human resource research, safety and health and employee relations, and in SHRP the dependent variables like employee security, recruitment, career planning, human capital management and extensive training.

Productive Human Resources Information System (HRIS): The productive human resources information system (HRIS) is essential in order manage the human resource in an organization. Before choosing human resource information system software the purchaser required to analyze determinants such as cost, quality, expected life, suitability, and other factors. On the other hand, we need to discuss the relationship between HRIS and the efficiency of employees. The traditional era of human resource management in a manual process was created confusions, inaccuracy, costly exercise, and fragmentation etc. So in order to avoid these problems, the error-free system is very essential. The human resources information system is a unique solution to overcome the problems, it enables the accuracy, user-friendliness, error-free, and less time consuming with transparency and trustfulness while maintaining and disclosing the data about a human resource.

Types of Human resource information system data: The types of human resource information system data includes the information about recruitment and 
selection, extensive training and development ,personnel statistics ,benefits administration, payroll statistics, and employees job related aspects like performance evaluation, appraisal, promotion ,transfers, union negotiations, employee training profiles ,training need, and finally the compensation management.

\section{CONCLUSION}

The finality of the study is not confined to only the above aspects, but the question is how the human resources information system is implemented by the organizations. As an organization we need think on different factors influencing on adoption of human resources information system in an organization. Such factors like the nature of the organization, head counts, structure of the organization etc. So I conclude that the human resources information system is a standardized tool to manage the workforce in a fruitful manner.The potential character of an HRIS is it acts a mechanism for efficient administration, by that the organization gets a sustainable and competitive advantage.

\section{REFERENCES}

1) Geraldine DeSanctis, Human Resource Information Systems: A Current Assessment, MIS Quarterly March 1986

2) John W. Boudreau, HR Information Systems: Exploiting the Full Potential, CAHRS working papers series 1996

3) Nicholas Aston Beadles, The Impact of Human Resource Information Systems: An Exploratory Study in the Public Sector, IIMA,2005
4) Ebenezer Ankrah \& Evans Soko, Human Resource Information System as A Strategic Tool in Human Resource Management, 2012

5) Patricia L Riley \& et al, Information systems on human resources for health: a global review, 2012

6) J. Anitha and M. Aruna, Adoption of Human Resource Information System in Organisations, SDMIMD Journal of Management,2013

7) Sabrina Jahan, Human Resources Information System(HRIS): A Theoretical Perspective, JHRSS, 2014, 2, 33-39

8) Halil Buzkan, The Role of Human Resource Information System (HRIS) in Organizations: $A$ Review of Literature, AJIS, 2016

9) Hanadi Al-Zeiger, The investigating the link between human resource information system and strategic human resource planning Field Study In The Jordanian Mobile Companies, Applied Science University, Amman, Jordan.

10) Dr, Manju Shukla \& et al, HRIS a review across states of India, 2014

11) https://sbionline.online/sbi-hrms-portal-login/

12) pbinfo.air.org.in/hrit/User\%20Guide/HRISUser\%20Guide.pdf

13) https://www.coalindia.in/en-us/ourpeople/hris.aspx and https://pnbnet.net.in/ 